\title{
RELAÇÃO ENTRE PRECIPITAÇÃO PLUVIOMÉTRICA E PRODUTIVIDADE DA CULTURA DE SOJA, NO MUNICÍPIO DE IBIRUBÁ-RS
}

\author{
Robson Rigão da Silva ${ }^{1}$ \\ Maria da Graça Barros Sartori (in memoriam) ${ }^{2}$ \\ Cássio Arthur Wollmann ${ }^{3}$
}

\begin{abstract}
Resumo: A presente pesquisa teve como objetivo geral avaliar a relação entre precipitação pluviométrica e produtividade de soja no município de Ibirubá - RS, como estudo de caso, no período de 31 anos (1982 a 2012). Os resultados foram organizados conforme a proposta metodológica deste trabalho, ou seja, com base no critério de precipitação, a qual foi subdividida em: precipitação abaixo da habitual precipitação habitual e precipitação acima da habitual. Dessa forma, os totais de precipitação pluviométricas influenciam nos rendimentos da soja, mas verificou-se que a distribuição hídrica durante o ciclo fenológico, em destaque os momentos com maior exigência hídrica, fase vegetativa de emergência e reprodutiva de enchimento do grão, tornaram-se fundamentais para os rendimentos finais. Mesmo com a introdução de novas tecnologias nos cultivares, como a soja de crescimento indeterminado, a variabilidade da precipitação pluviométrica ainda é influente na produtividade.
\end{abstract}

Palavras-chave: Precipitação pluviométrica; Produtividade; Soja; Ibirubá-RS.

\section{Rainfall relation and yield of soybean crop in the municipality of Ibirubá-RS}

\begin{abstract}
The present research concerns in evaluate the relationship between pluviometric precipitation and soybean productivity in the municipality of Ibirubá-RS, as a case study, in a period of 31 years (1982-2012). The results have been organized according to the methodological proposal of this work, in other words, based on precipitation criterion, which was subdivided into: precipitation below the usual, precipitation usual and precipitation above the usual. This way, the total of pluviometric precipitation influence the yields of soybeans, but it was verified that the hydric distribuition during the phenological cycle, in highlighted the moments with higher hydric requirement, vegetative phase of emergency and reproductive of grain filling have become essential for the final yields. Even with the introduction of new technologies in cultivars, such as soybeans indeterminate growth, variability of pluviometric precipitation is still influential in productivity.
\end{abstract}

Keywords: Rainfall; Productivity; Soybean; Ibirubá-RS.

\footnotetext{
${ }^{1}$ Licenciado em Geografia.Mestre em Geografia pela UFSM. E-mail: robsongeoufsm@hotmail.com

${ }^{2}$ Professora Titular Doutora - Universidade Federal de Santa Maria, Centro de Ciências Naturais e Exatas, Departamento de Geociências Curso de Geografia. (in memoriam)

${ }^{3}$ Geógrafo, doutor em Geografia Física pela Universidade de São Paulo. Professor Doutor - Universidade Federal de Santa Maria Centro de Ciências Naturais e Exatas, Departamento de Geociências, Curso de Geografia. Email: cassio_geo@yahoo.com.br
} 


\section{INTRODUÇÃO}

É inegável reconhecer os avanços tecnológicos que a humanidade obteve após a Revolução Industrial. Estas transformações foram causadoras de uma série de mudanças a nível mundial, pois "[...] ao transformar, ao longo do tempo, as formas de produzir e reproduzir os meios de sua própria sobrevivência, o ser humano modificou também suas relações humanas e com a natureza." (SAMPAIO; LEITE, 1999, p. 13).

Salienta Ayoade (2007) que os processos atmosféricos influenciam na biosfera, hidrosfera e litosfera, e nesse sentido, as atividades econômicas, tais como o comércio, indústria, transportes, comunicação e agricultura são afetados pelas variações meteorológicas em diversas escalas. Mesmo com o rápido progresso científico e tecnológico, o homem ainda é extremamente dependente das condições naturais, principalmente com ênfase na variável clima.

De acordo com Conti (2002), são inúmeras as formas pelas quais o clima afeta a vida humana e interfere na dinâmica do nosso planeta. É vigente a concepção que o clima é um condicionador da distribuição dos homens, animais e plantas na superfície terrestre, além de ser um zoneador dos cultivos agrícolas e de regular o ciclo hidrológico.

Monteiro (1981) afirmou que qualquer evento climático diferente dos padrões habituais resulta em uma reação em cadeia, reação esta que afeta não somente a produção agrícola como também acaba por prejudicar o ambiente, assim como os processos de organização agrícola afetam negativamente o quadro ecológico.

Qualquer sistema agrícola criado pelo homem depende do clima para funcionar, de forma semelhante ao ecossistema natural. Os principais fatores climáticos que afetam a produção agrícola são os mesmos elementos que influenciam a vegetação natural. Entre eles destacam-se a radiação solar, a temperatura e a umidade (OMETO, 1981).

O homem procura meios e técnicas que possam auxiliar na produção agrícola, já que não é capaz de mudar nem o tempo nem o clima, pelo menos não na escala macroclimática, mas com os recursos corretos, pode ajustar o manejo agrícola de acordo com as condições climáticas dominantes (PINTO; NETTO, 2008).

Assim, a abordagem da Climatologia Geográfica torna-se muito relevante no estudo do espaço agrícola, principalmente através da análise têmporo-espacial dos elementos 
climáticos e suas dependências em relação às diferentes culturas e seus ciclos vegetativos (RIBEIRO, 1993).

Os elementos atmosféricos, como: precipitação, temperatura, radiação solar, ventos, exercem influência sobre todos os estágios da produção agrícola. Neste sentido, Santos (1993) coloca que o tempo e o clima não exercem somente a sua influência na agricultura, mas que estes exercem influência em praticamente todas as atividades econômicas.

Em quase todas as fases das atividades agrícolas o clima assume papel principal. Para Mota (1983) tais atividades vão desde a seleção de regiões ou lugares para a instalação de culturas e experimentos agrícola, até o planejamento a longo ou curto prazo das referidas atividades. Neste sentido, estudos e pesquisas nas áreas de Agroclimatologia, Bioclimatologia vegetal ou climatologia agrícola, quando se procuram quantificar e estabelecer relações entre as variáveis condições atmosféricas versus plantas, estes mesmos estudos contribuem para prever safras, bem como prever aumentos na produtividade das culturas.

De acordo com Ayoade (2007), cada região produtora, apresenta elementos climáticos com diferentes variabilidades ao longo do ano e, por isso, se faz necessário o estudo da influência do clima em uma determinada região, conclui o autor.

Os avanços tecnológicos e científicos modificaram muito a vida do agricultor, dando maiores possibilidades para resistir à variabilidade do tempo, no entanto, o clima continua sendo uma variável importante para a agricultura (Sartori, 2005)

A cultura da soja, de acordo com Pizzi; Trindade (2008), não foge a esta regra, pois se caracteriza principalmente por demandar um alto valor de investimentos, em função do elevado grau de tecnologia empregado no processo, garantindo assim, uma rentabilidade econômica e social.

Nesse sentido, o presente trabalho teve como objetivo geral avaliar a relação entre precipitação pluviométrica e produtividade de soja no município de Ibirubá - RS, como estudo de caso, no período de 31 anos (1982 a 2012).

Foram estabelecidos como objetivos específicos:

(1) Avaliar a distribuição anual e a relação da precipitação com as fases do ciclo fenológico da soja durante os anos-safra do cultivo.

(2) Analisar os anos padrões mais significativos no que se refere a maior e menor precipitação, identificados como anos-padrões mais chuvosos, menos chuvosos, e habituais 
que influenciaram na maior e/ou menor produtividade de soja no município de Ibirubá, no período de 1982 a 2012.

(3) Identificar e relacionar, por meio do Balanço Hídrico climatológico, a influência da variabilidade pluviométrica nos rendimentos finais da soja ao longo dos anos-safra mais significativos.

\section{PROCEDIMENTOS METODOLÓGICOS}

Primeiramente, foi elaborado um embasamento teórico geral do tema e objetivos do trabalho, bem como da justificativa para sua escolha. Em seguida, partiu-se para a fundamentação teórico-metodológica referente à temática, onde a discussão está centrada no clima e produção agrícola, com ênfase na produção de soja.

Para estabelecer a relação entre pluviometria e produtividade (rendimentos) de soja foi feita a coleta dos dados mensais e anuais de precipitação junto a Estação Meteorológica Auxiliar do Instituto Nacional de Meteorologia (INMET), localizada no município de Ibirubá/RS (latitude 28 37' S e longitude 53 70' W, e altitude 349,7 metros) para o período de 1982 a 2012, e dados da produtividade de soja na Cooperativa Mista General Osório - COTRIBÁ e da Empresa de Assistência Técnica e Extensão Rural - Emater, para mesmo período.

Como as técnicas agrícolas evoluíram muito ao longo dos últimos anos no planeta e com reflexos no Brasil, bem como, no estado do Rio Grande do Sul, foi analisado um histórico a respeito das técnicas agrícolas tradicionais e modernas aplicadas no município a fim de comparar a produção não só com a precipitação, mas também com o manejo utilizado.

Diante disso optou-se por avaliar através do balanço hídrico os anos-safras, sempre os mais recentes e representativos, com rendimentos altos, médios e baixos de cada período pluviométrico, ou seja, de acordo com o padrão habitual, habitual muito chuvoso e habitual pouco chuvoso. Além disso, os anos-safra selecionados para análise através do balanço hídrico, foram a partir de 1990, para que a técnica do plantio direto influenciasse de forma menos significativa nos rendimentos finais, bem como, aqueles que tenham registro de ENOS (El Niño e La Niña), (WOLLMANN, 2011).

Nos estudos de Climatologia Geográfica, tem sido utilizado o ano padrão civil, ou seja, os doze meses do ano (janeiro à dezembro). No entanto, para os estudos de bioclimatologia vegetal o uso desse segmento temporal não parece ser o mais indicado, uma vez que a 
maioria das culturas têm o ciclo vegetativo sazonal, principalmente nas regiões onde o clima se caracteriza por alternância entre estações secas e chuvosas (por exemplo, no CentroOeste do Brasil) ou de estações com maiores ou menores temperaturas médias mensais (Regiões Sudeste e Sul), caso do soja, milho, trigo, uva. Estas culturas têm um período vegetativo que não abrange os doze meses do ano, e que pode ser caracterizado como anosafra.

$\mathrm{Na}$ identificação e análise das variações mensais e anuais que ocorreram na distribuição da precipitação ao longo de 30 anos (1982-2012), no município de Ibirubá, levou-se em consideração o período de setembro a maio e da produção de soja para o mesmo período. Apesar do início do plantio de soja ocorrer em média nos meses de outubro a dezembro, o mês de setembro foi incluído dentro dos Anos-safra para verificar a possibilidade da influência da precipitação acumulada, ou seja, que a capacidade de água acumulada no solo possa influenciar no início do ciclo fenológico da soja (emergência - VE).

A partir dos dados de precipitação e rendimentos elaboraram-se tabelas relativas aos valores médios mensais e anuais de pluviometria e os totais de rendimento em cada anosafra que resultaram em gráficos, estes gerados no programa Microsoft Excel 2007.

Através do uso da planilha com dados da produção de soja, foram plotados gráficos gerados no programa Microsoft Excel 2007, correspondentes aos anos padrões-safra estudados a fim de estabelecer a relação do total colhido e da produtividade média das lavouras no Município com os valores e distribuição mensal das chuvas. Nesta fase foi importante identificar em que fase do ciclo vegetativo da planta ocorreram os excessos e a escassez de chuvas nos anos padrões selecionados, que podem ser capazes de comprometer os valores de produção no município de Ibirubá.

Após a elaboração da planilha, definiram-se os anos padrões-safra chuvosos, os menos chuvosos e os habituais, utilizando-se o critério de Wollmann (2011) para os estudos climatológicos do ponto de vista geográfico, para a análise da variabilidade dos elementos meteorológicos.

Em um primeiro momento foi calculada a Normal Climatológica anual para o período considerado como ano-safra (setembro a maio), que corresponde a apenas nove meses entre dois civis. Em um segundo momento, foi necessário calcular a média para cada mês do período analisado a fim de obter a distribuição das chuvas ao longo dos considerados anos padrão habitual, mais chuvoso e menos chuvoso. 
A partir da montagem da planilha foram colocados os dados de precipitação total e médias dos anos-safras juntamente com o rendimento médio ( $\mathrm{kg} / \mathrm{ha}$ por ano-safra) da produtividade de soja do município de Ibirubá. Na sequência, foram selecionados os valores mínimos e máximos de precipitação de cada mês e valores médios correspondentes ao período de 30 anos (1982/83-2011/12).

Dessa forma, para cada mês obtiveram-se nove valores mínimos e nove máximos de pluviometria correspondentes aos anos-safra. Por fim, ocorreu o cálculo do desvio padrão, proposto por Gerardi; Silva (1981), da precipitação de cada mês dos anos-safra juntamente com o desvio padrão das médias e totais dos anos-safra com objetivo de demonstrar os padrões habitual, menos chuvoso e mais chuvoso a fim de verificar a relação da pluviometria com os valores de rendimentos.

Concomitantemente também foram selecionados para análise os totais da produção de soja no município no período 1982/83-2011/12, levando em conta a área plantada (ha), quantidade produzida (ton) e rendimento médio da produção $(\mathrm{kg} / \mathrm{ha})$.

Segundo Farias; Nepomuceno; Neumaier (2007) a necessidade total de água na cultura da soja, para obtenção de máximo rendimento, varia entre 450 a $800 \mathrm{~mm} /$ ciclo fenológico. Ao considerar o ciclo vegetativo médio de 120 dias para a cultura da soja e o período recomendado para semeadura novembro, bem como, colheita em março de acordo com as recomendações da Embrapa Soja (2001).

Após a análise dos dados das planilhas e dos gráficos de precipitação e rendimentos dos anos safra de 1982/83 até 2011/12 obteve-se quadros com rendimentos baixos, médios e altos de soja de acordo com a precipitação dos anos-padrões-safra abaixo da habitual, habitual e acima da habitual. Analisou-se também a importância da distribuição da precipitação ao longo do ciclo fenológico da soja.

Na planilha, que será posteriormente apresentada, após a aplicação do desvio padrão, foram destacados (em verde) a precipitação (normal) e rendimentos habituais dentro do padrão habitual, os tons de azul foram usados para destacar os anos padrões pluviométricos (muito chuvoso) e de rendimentos acima do padrão e, por fim os tons de vermelhos foram utilizados para representar os anos padrões com menores rendimentos e de menores precipitações (menos chuvosos). 
Utilizando o critério de precipitação, padrão habitual, acima do padrão habitual e abaixo do padrão habitual, foram distribuídos os 30 anos-safra com rendimentos altos, médios e baixos dentro de cada índice pluviométrico.

Posteriormente, foram selecionados para análise mais aprofundada um ano-safra de cada dos 3 grupos pluviométrico (acima, abaixo e habitual), ou seja, um ano safra com rendimento alto, médio e baixo dentro de grupo de precipitação. Foi utilizado também, na escolha dos anos-safra, os registros de ENOS EI Niño e La Niña a fim de verificar sua influencia nos rendimentos finais. Em todos estes anos-safra selecionados furam gerados gráficos de cada ano-safra com a precipitação mensal.

Para elucidar algumas dúvidas em relação aos resultados obtidos foi elaborado o calculo do Balanço Hídrico, proposto por Thornthwaite; Mather (1955), considerando os ciclos característicos (fenologia) de desenvolvimento dos cultivares ao longo de anos padrões escolhidos, com o objetivo de entender mais claramente em quais fases do ciclo vegetativo (fenologia) se definem os excessos e carência de chuva e que podem influenciar mais no rendimento da lavoura.

No sítio <http://ce.esalq.usp.br/bhbrasil> encontra-se disponível o balanço hídrico para 500 localidades do Brasil, sendo que deste total 268 localidades são do municípios do Estado de São Paulo. Se for necessário obter o balanço hídrico climatológico para uma localidade fora do sítio é preciso substituir os valores de temperatura, precipitação e latitude do local que será automaticamente realizado todos os cálculos e gráficos, possibilitando a análise dos períodos secos e úmidos (GALVANI, 2005).

Por fim, os anos-safra de 1996/97; 1997/98; 2004/05; 2007/08; 2009/10 e 2011/12; foram selecionados para a elaboração do balanço hídrico climatológico com o objetivo de compreender melhor de que forma a distribuição da precipitação durante o ciclo fenológico da soja, pode influenciar nos rendimentos finais.

\section{RESULTADOS E DISCUSSÕES}

Os resultados foram organizados conforme a proposta metodológica deste trabalho, ou seja, com base no critério de precipitação, a qual foi subdividida em: precipitação abaixo da habitual (normal - quadro 2); precipitação habitual (normal - quadro 3) e precipitação acima da habitual (normal - quadro 4). 


\section{Precipitação abaixo da habitual (normal).}

Dos 30 anos-safra analisados (1982/1983 a 2011/2012), foram registrados 3 anos-safra com produtividade e a precipitação abaixo da habitual (quadro 1 e 2, respectivamente). Nestes anos não houve rendimento alto, ou seja, acima dos valores médios (entre 1468,9 kg/ha $2680,4 \mathrm{~kg} / \mathrm{ha}$ ). Os rendimentos médios totalizaram 33,3\% (ano-safra 1996/97) do total de registros. Por fim, os rendimentos abaixo dos valores médios, anos safra de 1985/86 e 2011/12 totalizaram $66,7 \%$ dos registros de precipitação abaixo da habitual.

Quadro 1: Precipitação abaixo da habitual (normal) - 3 registros

\begin{tabular}{|c|c|c|}
\hline Rendimento & Ano-safra & Total de registros \\
\hline Alto & - & 0 \\
\hline Médio & safra 1996/97; & $1(33,3 \%)$ \\
\hline Baixo & safra 1985/86; safra 2011/12 & $2(66,7 \%)$ \\
\hline
\end{tabular}

Org.: SILVA, R. R. (2013).

Salienta-se que ao analisar os dados, precipitação média dos anos-safra e rendimento da soja, verificou-se, conforme Santos; Ribeiro (2002); Almeida (2005); Berlato; Cordeiro (2005) que a precipitação abaixo da habitual foi relevante na queda da produtividade da soja. Esses rendimentos abaixo da média (menor 1468,9 kg/ha) ocorreram nas safras de 1985/86 e $2011 / 12$ os quais registraram valores de $1300 \mathrm{~kg} / \mathrm{ha}$ e $1380 \mathrm{~kg} / \mathrm{ha}$ respectivamente.

Constatou-se que os totais de precipitação, dos meses referidos, do ano-safra 1985/86 foi de $436,8 \mathrm{~mm}$ de chuva; ano-safra $1996 / 97$ foi de $471,4 \mathrm{~mm}$ de chuva e ano-safra $2011 / 12$ foi de 497,0mm de chuva ficaram abaixo e próximos dos valores totais mínimos exigidos $(450 \mathrm{~mm} /$ ciclo fenológico) para alto rendimento do grão como mostram respectivamente as figuras 1,2 e 3.

Além dos totais médios estarem próximos ou abaixo do considerado ideal para obtenção dos máximos rendimentos da soja, a distribuição da precipitação, também auxilia na compreensão da queda dos rendimentos nos anos-safra 1985/86, e 2011/12. Tal fato vai ao encontro dos estudos de Almeida (2000); Berlato; Cordeiro (2005); Souza; Silva, (2012) os quais comprovaram que as maiores variações dos rendimentos da soja coincidem com a maior variabilidade de precipitação pluvial. 
Quadro 2: Dados anos-safra com precipitação abaixo da habitual no município de Ibirubá-RS - anos-safra abaixo da precipitação habitual (normal).

\begin{tabular}{|c|c|c|c|c|c|c|c|c|c|c|c|c|}
\hline $\begin{array}{c}\text { Ano- } \\
\text { safra } \\
\text { Meses } \\
\end{array}$ & set. & out. & nov. & dez. & jan. & fev. & mar & abr. & maio & $\begin{array}{l}\text { Precip } \\
\text { média }\end{array}$ & $\begin{array}{c}\text { Precip. } \\
\text { total }\end{array}$ & $\begin{array}{l}\text { Rendimento } \\
\text { médio (kg/ha) }\end{array}$ \\
\hline $1985 / 86$ & 176,0 & 35,7 & 7,3 & $\begin{array}{c}127 \\
0 \\
\end{array}$ & 47,6 & 103,0 & $\begin{array}{c}151, \\
9 \\
\end{array}$ & $\begin{array}{c}224 \\
9 \\
\end{array}$ & $\begin{array}{c}205 \\
1 \\
\end{array}$ & 119,8 & 1078,5 & $1.300 \mathrm{~kg} / \mathrm{ha}$ \\
\hline 1996/97 & 84,4 & 186,7 & 166,1 & 79,7 & 73,7 & 116,1 & 35,8 & 87,0 & 99,8 & 103,3 & 929,3 & $1.680 \mathrm{~kg} / \mathrm{ha}$ \\
\hline $2011 / 12$ & 54,0 & 160,3 & 56,7 & 42,8 & 129,6 & 136,5 & $\begin{array}{c}131 \\
4\end{array}$ & 57,7 & 34,2 & 89,2 & 803,2 & $1.380 \mathrm{~kg} / \mathrm{ha}$ \\
\hline $\begin{array}{c}\text { Média } \\
\text { mensal } \\
\text { hist. }\end{array}$ & $\begin{array}{c}186 \\
4\end{array}$ & $\begin{array}{c}217 \\
7\end{array}$ & $\begin{array}{c}169 \\
9\end{array}$ & $\begin{array}{c}141 \\
6\end{array}$ & 167,5 & 157,7 & $\begin{array}{c}121 \\
5\end{array}$ & $\begin{array}{c}172 \\
3\end{array}$ & $\begin{array}{c}141 \\
8\end{array}$ & 164,0 & 1476,4 & $2080 \mathrm{~kg} / \mathrm{ha}$ \\
\hline $\begin{array}{c}\text { Mín. } \\
\text { precip. }\end{array}$ & 54,0 & 35,7 & 7,3 & 42,8 & 46,5 & 19,3 & 23,2 & 14,6 & 12,4 & 89,2 & 803,2 & $600 \mathrm{~kg} / \mathrm{ha}$ \\
\hline $\begin{array}{l}\text { Desvio } \\
\text { padrão }\end{array}$ & $\begin{array}{c}106 \\
7\end{array}$ & $\begin{array}{c}120, \\
2\end{array}$ & $\begin{array}{c}132, \\
3\end{array}$ & 90,3 & 97,7 & 116,0 & 64,7 & 91,3 & 90,4 & 41,9 & 377,0 & $611,5 \mathrm{~kg} / \mathrm{ha}$ \\
\hline $\begin{array}{l}\text { Máx. } \\
\text { precip. }\end{array}$ & $\begin{array}{c}438, \\
1 \\
\end{array}$ & $\begin{array}{c}595 \\
7 \\
\end{array}$ & $\begin{array}{c}477, \\
4 \\
\end{array}$ & $\begin{array}{c}408, \\
1 \\
\end{array}$ & 390,8 & 507,5 & $\begin{array}{c}288, \\
1 \\
\end{array}$ & $\begin{array}{c}455 \\
6 \\
\end{array}$ & $\begin{array}{c}366, \\
1 \\
\end{array}$ & 261,1 & 2350,3 & $3300 \mathrm{~kg} / \mathrm{ha}$ \\
\hline \multicolumn{12}{|c|}{ Classificação dos padrões de precipitação em mm } & $\begin{array}{l}\text { Classif. dos } \\
\text { rendim. kg/ha }\end{array}$ \\
\hline $\begin{array}{l}\text { Muito } \\
\text { chuvoso }\end{array}$ & $\begin{array}{c}293, \\
1 \\
\end{array}$ & $\begin{array}{c}337, \\
8 \\
\end{array}$ & $\begin{array}{c}302, \\
2 \\
\end{array}$ & $\begin{array}{c}231, \\
9\end{array}$ & 265,1 & 273,7 & $\begin{array}{c}186, \\
2\end{array}$ & $\begin{array}{c}263 \\
6\end{array}$ & $\begin{array}{c}232, \\
2 \\
\end{array}$ & 205,9 & 1853,4 & $2680,4 \mathrm{~kg} / \mathrm{ha}$ \\
\hline $\begin{array}{c}\text { Total de } \\
\text { dias }\end{array}$ & 5 & 5 & 5 & 4 & 7 & 4 & 5 & 4 & 4 & 5 & 5 & 6 \\
\hline Habitual & $\begin{array}{c}293,1 \\
- \\
79,6\end{array}$ & $\begin{array}{c}337,8 \\
- \\
97,5\end{array}$ & $\begin{array}{c}302,2 \\
- \\
37,7\end{array}$ & $\begin{array}{c}231 \\
9- \\
51,3\end{array}$ & $\begin{array}{c}265,1 \\
4- \\
69,8\end{array}$ & $\begin{array}{c}273,7 \\
3- \\
41,8\end{array}$ & $\begin{array}{c}186 \\
2- \\
56,8\end{array}$ & $\begin{array}{c}263 \\
6- \\
81,0\end{array}$ & $\begin{array}{c}232 \\
2- \\
51,4\end{array}$ & $\begin{array}{c}205,9 \\
- \\
122,2\end{array}$ & $\begin{array}{c}1853,4 \\
- \\
1099,4\end{array}$ & $\begin{array}{c}\text { entre } \\
1468,9 \mathrm{~kg} / \mathrm{ha} \mathrm{e} \\
2680,4 \mathrm{~kg} / \mathrm{ha}\end{array}$ \\
\hline $\begin{array}{l}\text { Total de } \\
\text { dias }\end{array}$ & 23 & 21 & 23 & 24 & 20 & 23 & 20 & 23 & 19 & 22 & 22 & 19 \\
\hline $\begin{array}{l}\text { Menos } \\
\text { chuvoso }\end{array}$ & 79,6 & 97,5 & 37,7 & 51,3 & 69,8 & 41,8 & 56,8 & 81,0 & 51,4 & 122,2 & 1099,4 & 1468,9 kg/há \\
\hline $\begin{array}{c}\text { Total de } \\
\text { dias }\end{array}$ & 2 & 4 & 2 & 2 & 3 & 3 & 5 & 3 & 7 & 3 & 3 & 5 \\
\hline
\end{tabular}

Org.: SILVA, R. R. (2013)

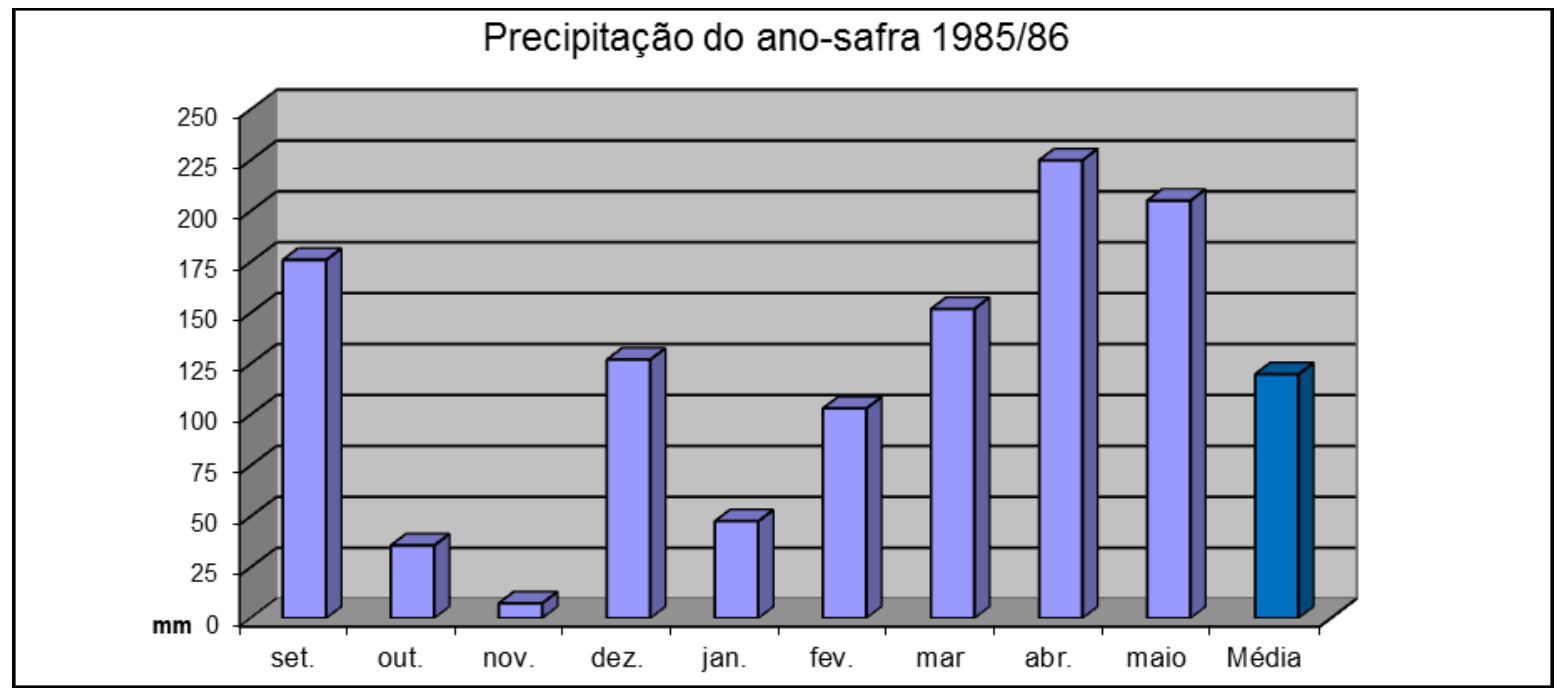

Figura 1: Ano-safra 1985/86 com precipitação abaixo da habitual (normal) Fonte: INMET - Estação Meteorológica do município de Ibirubá Org.: SILVA, R. R. (2013) 
Os registros de precipitação deficitária durante os períodos mais críticos do ciclo fenológico (período vegetativo e floração/formação do grão) foram determinantes para queda nos rendimentos. Os meses de outubro, novembro e janeiro do ano-safra de 1985/86 registraram precipitação abaixo do padrão habitual mensal. Já no ano-safra de 2011/12 a precipitação abaixo do padrão habitual mensal ocorreu nos meses de setembro, dezembro, abril e maio. Confirma-se, então que o déficit hídrico nos períodos fenológicos de maior exigência hídrica contribuíram para queda na produtividade destes anos-safra.

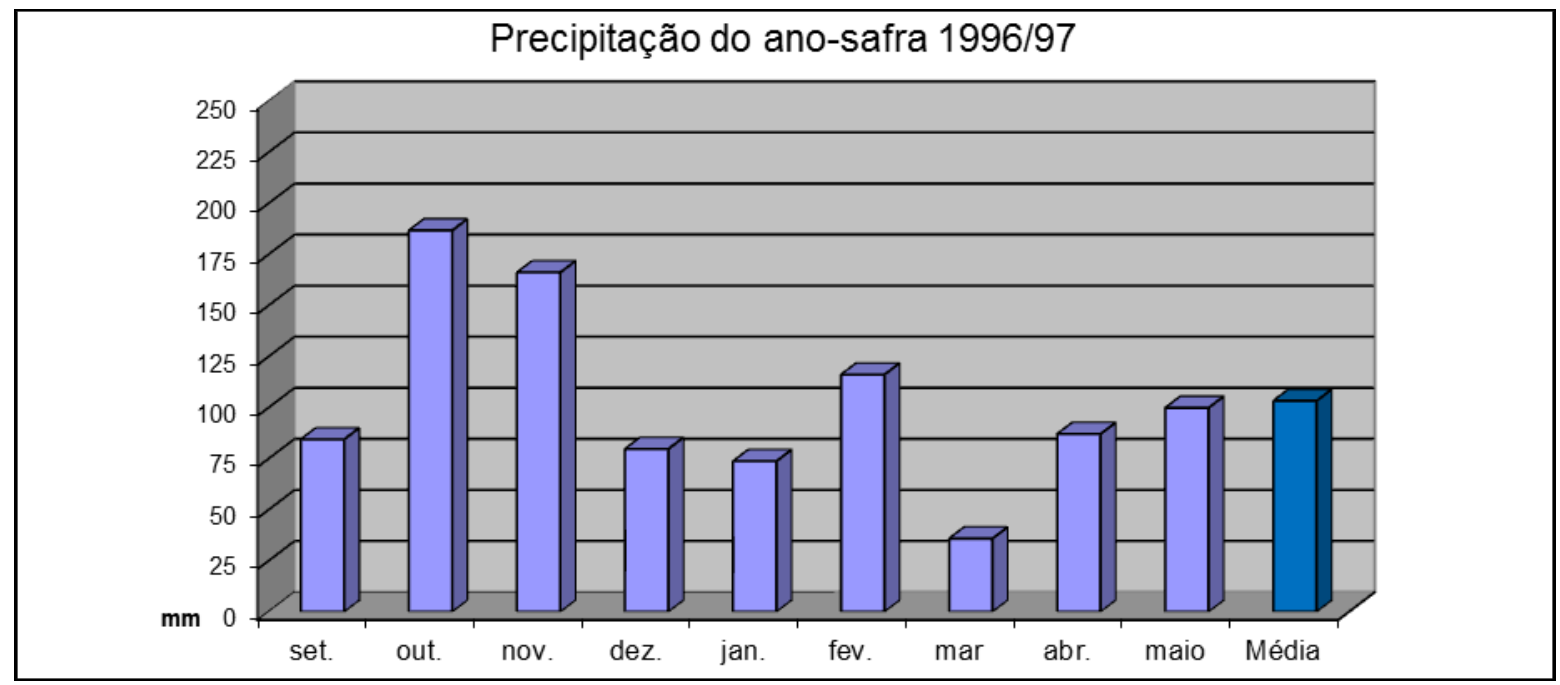

Figura 2: Ano-safra 1996/97 com precipitação abaixo da habitual (normal)

Fonte: INMET - Estação Meteorológica do município de Ibirubá Org.: SILVA, R.R (2013).

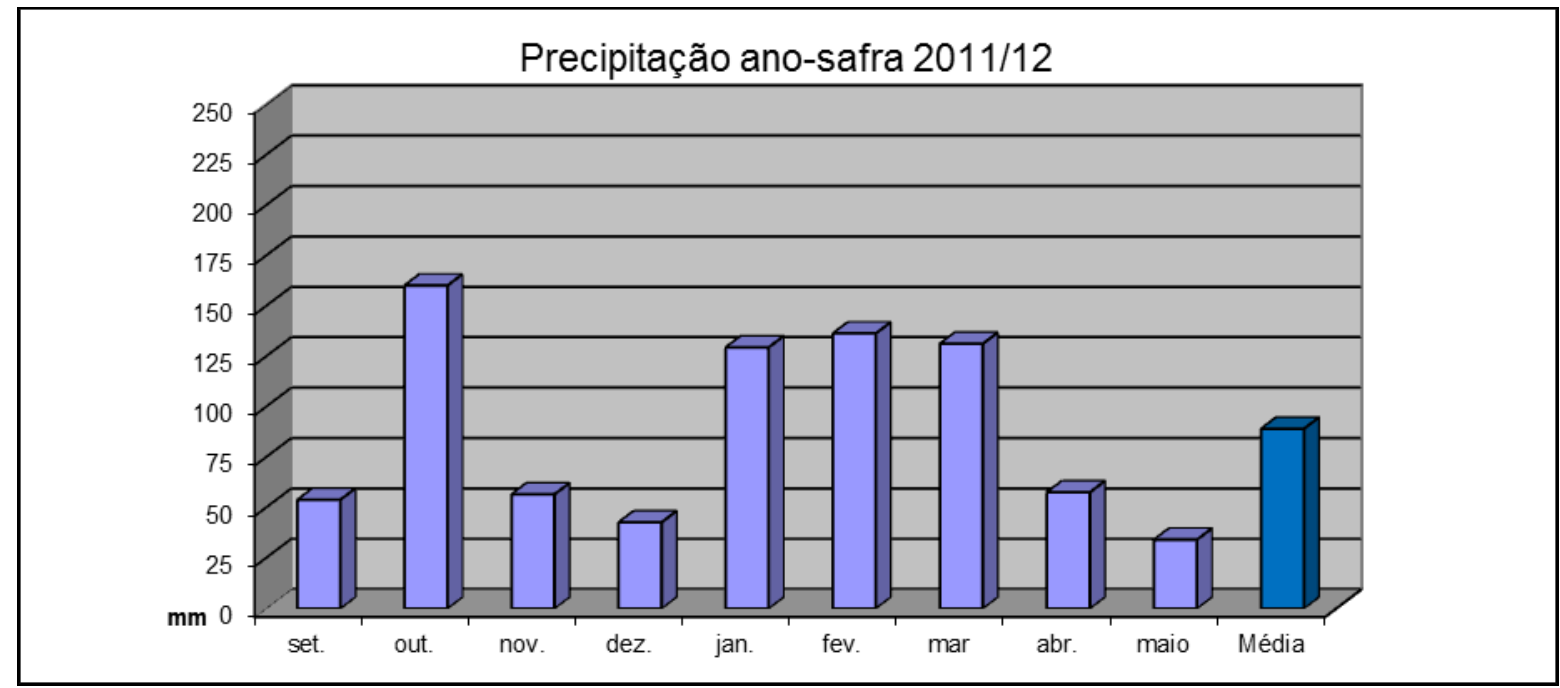

Figura 3: Ano-safra 2011/12 com precipitação abaixo da habitual (normal) Fonte: INMET - Estação Meteorológica do município de Ibirubá Org.: SILVA, R. R. (2013).

Observou-se também, que a média mensal histórica (quadro 3) para os meses de novembro, dezembro, janeiro e fevereiro, nota-se que em quase a totalidade dos anos-safra analisados 
a precipitação esteve abaixo da média mensal histórica. Os meses em questão correspondem aos períodos de emergência (VE), vegetativo (VC), floração (R1-R2), desenvolvimento da vagem (R3-R4) e formação do grão (R5-R6), (FARIAS; NEPOMUCENO; NEUMAIER, 2007).
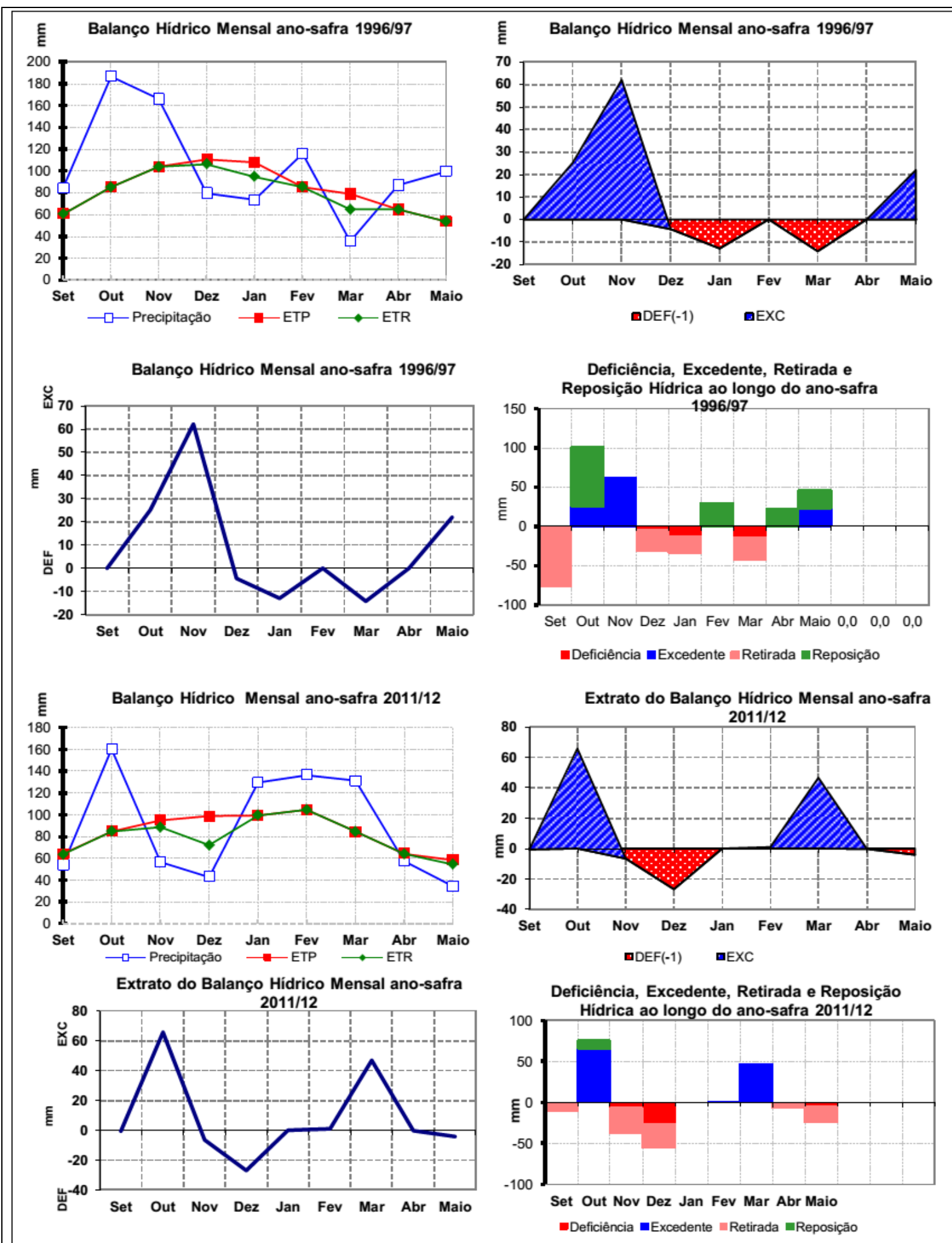

Figura 4: Balanço Hídrico do ano-safra 1996/97 e ano-safra 2011/12 Org.: SILVA, R. R. (2013). 
Através da utilização do balanço hídrico, elaborado por Thornthwaite; Mather, (1955) e aplicado para anos-safra de 1996/97 e 2011/12 (figura 4), auxiliou na confirmação de que não só a precipitação abaixo do padrão médio, mas também, sua distribuição durante os principais períodos do ciclo fenológico da soja, foram determinantes para justificar a queda nos rendimentos na cultura no município de Ibirubá (SENTELHAS et al. 2003; GALVANI, 2004; MARIANO; SANTOS, 2006).

O ano safra de 1996/97 registrou precipitação total de $471,4 \mathrm{~mm}$ entre os meses de novembro e março, valor considerado próximo do mínimo exigido, (450 a $800 \mathrm{~mm} /$ ciclo fenológico) de acordo com Farias; Nepomuceno; Neumaier (2007), para obtenção de máximos rendimentos. Porém, este ano-safra registrou rendimento final de $1680 \mathrm{~kg} / \mathrm{ha}$, ou seja, entre os valores de $1468,9 \mathrm{~kg} / \mathrm{ha}$ e $2680,4 \mathrm{~kg} / \mathrm{ha}$ considerados de produtividade média. A distribuição mais regular da precipitação no ano-safra de 1996/97, em relação aos dois outros anos-safra (1985/86 e 2011/12), durante o ciclo fenológico da planta pode ter levado a obtenção de rendimentos médios, mesmo que este ano-safra seja classificado como abaixo do padrão habitual pluviométrico. Nota-se que o mês de março apresentou valor de precipitação de $35,8 \mathrm{~mm}$. Este valor ficou abaixo do padrão habitual mensal durante as fases R7-R8 da soja, momento em que, segundo Cunha et al. (2001); confirmado também por Farias; Nepomuceno; Neumaier (2007), a deficiência hídrica não comprometeu de forma significativa o rendimento final do grão. Os meses, novembro, janeiro fevereiro, registraram totais pluviométricos dentro do padrão habitual mensal e, dessa forma, garantiram as necessidades hídricas mínimas durante o período vegetativo (VE- $\mathrm{Vn}$ ) e período reprodutivo (R1-R6) da soja, os mais significativos para os rendimentos finais.

É importante destacar, conforme mostra o balanço hídrico, que o excedente de precipitação em outubro e novembro, juntamente com a reposição hídrica no mês de fevereiro, podem ter sido suficientes para garantir rendimentos dentro do padrão médio. Dessa forma, segundo o calendário médio para a cultura da soja o mês de dezembro corresponderia ao período vegetativo de emergência (VE-VC). A precipitação acumulada dos meses de outubro e novembro podem ter auxiliado na germinação em dezembro devido à capacidade de armazenamento de água no solo. Já a reposição hídrica do mês de fevereiro pode ter auxiliado aos períodos de floração/formação do grão (R1 - R6) minimizando assim possíveis perdas nos rendimentos finais. 


\section{Precipitação habitual (normal).}

Dos 30 anos-safra analisados (1982/1983 a 2011/2012), foram registrados 22 anos-safra com precipitação habitual (normal) conforme mostra o quadro 3. Apesar da precipitação dentro do padrão habitual os rendimentos foram variáveis e uma das possíveis explicações pode ser a elevada variabilidade pluviométrica durante o ciclo fenológico da soja dos anos-safra analisados.

Quadro 3: Precipitação habitual (normal) - 22 registros e rendimentos

\begin{tabular}{|c|c|c|}
\hline Rendimento & Ano-safra & $\begin{array}{c}\text { Total de } \\
\text { registros }\end{array}$ \\
\hline Alto & safra 2000/01; safra 2002/03; safra 2006/07; safra 2007/08; safra & $5(22,7 \%)$ \\
\hline \multirow{2}{*}{ Médio } & $\begin{array}{c}\text { safra 1983/09; } \\
\text { 1991/92; safra 1992/93; safra 1994/95; safra 1995/96; safra }\end{array}$ & \multirow{2}{1}{ 19 (66,6\%) } \\
& $\begin{array}{c}\text { 1998/99; safra 1999/00; safra 2001/02; safra 2003/04; safra } \\
\text { 2005/06; safra 2010/11; }\end{array}$ & $3(10,7 \%)$ \\
\hline
\end{tabular}

$$
\text { Org: SILVA, R. R. (2013). }
$$

Os anos-safra com rendimentos altos, acima de $2680,4 \mathrm{~kg} / \mathrm{ha}$, totalizaram $22,7 \%$ (5 anossafra) dos registros. Os rendimentos médios, entre $1468,9 \mathrm{~kg} / \mathrm{ha}$ e $2680,4 \mathrm{~kg} / \mathrm{ha}$ totalizaram $66,6 \%$ (14 anos-safra) do total de registros. Por fim, os rendimentos baixos, menores que $1468,9 \mathrm{~kg} / \mathrm{ha}$ totalizaram $10,7 \%$ (3 anos-safra) dos registros de precipitação habitual.

Foram selecionados os anos-safra de: 2004/05 (baixo rendimento com registro de fenômeno El Niño); 2007/08 (alto rendimento com registro de fenômeno de La Niña); e 2010/11 (rendimento médio sem registro de ENOS) para uma análise mais criteriosa conforme quadro 4.

Segundo Farias; Nepomuceno; Neumaier (2007) a necessidade total de água na cultura da soja, para obtenção de máximo rendimento, varia entre 450 a $800 \mathrm{~mm} /$ ciclo fenológico. Ao considerar o ciclo vegetativo médio de 120 dias para a cultura da soja e o período recomendado para semeadura novembro, bem como, colheita em março de acordo com as recomendações da Embrapa Soja (2001), constatou-se que os totais de precipitação, dos meses referidos, do ano-safra 2004/05 foi de 497,5mm de chuva; ano-safra 2007/08 foi de $632,0 \mathrm{~mm}$ de chuva e ano-safra $2010 / 11$ foi de $1065,2 \mathrm{~mm}$ de chuva. Estes valores pluviométricos dos anos-safra ficaram próximos do total mínimo, ano-safra 2004/05 (450mm/ciclo fenológico), acima dos totais máximos, ano-safra 2010/11, (800mm/ciclo 
fenológico), e valor intermediário, ano-safra 2007/08, entre os mínimos e máximos recomendados para obtenção de altos rendimentos.

Quadro 4: Dados anos-safra selecionados com precipitação habitual no município de Ibirubá-RS - anos-safra selecionados com precipitação habitual

\begin{tabular}{|c|c|c|c|c|c|c|c|c|c|c|c|c|}
\hline \multirow{2}{*}{$\begin{array}{c}\text { Meses } \\
\text { Anos- } \\
\text { safra }\end{array}$} & \multirow[b]{2}{*}{ set. } & \multirow[b]{2}{*}{ out. } & \multirow[b]{2}{*}{ nov. } & \multirow[b]{2}{*}{ dez. } & \multirow[b]{2}{*}{ jan. } & \multirow[b]{2}{*}{ fev. } & \multirow[b]{2}{*}{ mar } & \multirow[b]{2}{*}{ abr. } & \multirow[b]{2}{*}{ maio } & \multicolumn{2}{|c|}{ Precipitação } & \multirow{2}{*}{$\begin{array}{l}\text { Rendimento } \\
\text { médio (kg/ha) }\end{array}$} \\
\hline & & & & & & & & & & Média & Total & \\
\hline $\begin{array}{c}2004 / 0 \\
5 \\
\end{array}$ & 158,0 & 140,2 & 181,3 & 84,2 & 118,3 & 19,3 & 93,9 & 213,5 & 204,8 & 134,8 & 1213,5 & $600 \mathrm{~kg} / \mathrm{ha}$ \\
\hline $\begin{array}{c}2007 / 0 \\
8 \\
\end{array}$ & 403,1 & 218,5 & 132,7 & 141,5 & 192,2 & 112 & 53,6 & 146,8 & 104,6 & 167,2 & 1505,0 & $2.900 \mathrm{~kg} / \mathrm{ha}$ \\
\hline $\begin{array}{c}2010 / 1 \\
1\end{array}$ & 271,1 & 103,4 & 98,8 & 131,1 & 73,8 & 473,4 & 288,1 & 213,1 & 101,2 & 194,9 & 1754,0 & $2.520 \mathrm{~kg} / \mathrm{ha}$ \\
\hline $\begin{array}{l}\text { Média } \\
\text { mensal }\end{array}$ & 186,4 & 217,7 & 169,9 & 141,6 & 167,5 & 157,7 & 121,5 & 172,3 & 141,8 & 164,0 & 1476,4 & $2080 \mathrm{~kg} / \mathrm{ha}$ \\
\hline $\begin{array}{l}\text { Mín. } \\
\text { precip. }\end{array}$ & 54,0 & 35,7 & 7,3 & 42,8 & 46,5 & 19,3 & 23,2 & 14,6 & 12,4 & 89,2 & 803,2 & $600 \mathrm{~kg} / \mathrm{ha}$ \\
\hline $\begin{array}{l}\text { Desvio } \\
\text { padrão }\end{array}$ & 106,7 & 120,2 & 132,3 & 90,3 & 97,7 & 116,0 & 64,7 & 91,3 & 90,4 & 41,9 & 377,0 & $611,5 \mathrm{~kg} / \mathrm{ha}$ \\
\hline $\begin{array}{c}\text { Max. } \\
\text { precip. }\end{array}$ & 438,1 & 595,7 & 477,4 & 408,1 & 390,8 & 507,5 & 288,1 & 455,6 & 366,1 & 261,1 & 2350,3 & $3300 \mathrm{~kg} / \mathrm{ha}$ \\
\hline \multicolumn{12}{|c|}{ Classificação dos anos-padrões de precipitação em mm } & $\begin{array}{l}\text { Classif. dos } \\
\text { rendim. } \mathrm{Kg} / \mathrm{ha}\end{array}$ \\
\hline $\begin{array}{l}\text { Muito } \\
\text { chuvos } \\
0\end{array}$ & 293,1 & 337,8 & 302,2 & 231,9 & 265,1 & 273,7 & 186,2 & 263,6 & 232,2 & 205,9 & 1853,4 & $2680,4 \mathrm{~kg} / \mathrm{ha}$ \\
\hline $\begin{array}{c}\text { Total } \\
\text { de dias }\end{array}$ & 5 & 5 & 5 & 4 & 7 & 4 & 5 & 4 & 4 & 5 & 5 & 6 \\
\hline $\begin{array}{l}\text { Habitu } \\
\text { al }\end{array}$ & $\begin{array}{l}293,1 \\
-79,6\end{array}$ & \begin{tabular}{|}
337,8 \\
$-97,5$
\end{tabular} & $\begin{array}{r}302,2 \\
-37,7\end{array}$ & $\begin{array}{r}231,9 \\
-51,3\end{array}$ & $\begin{array}{c}265,1 \\
4- \\
69,8\end{array}$ & $\begin{array}{c}273,7 \\
3- \\
41,8\end{array}$ & $\begin{array}{r}186,2 \\
-56,8\end{array}$ & $\begin{array}{r}263,6 \\
-81,0\end{array}$ & $\begin{array}{r}232,2 \\
-51,4\end{array}$ & $\begin{array}{c}205,9 \\
- \\
122,2\end{array}$ & $\begin{array}{c}1853,4- \\
1099,4\end{array}$ & $\begin{array}{c}\text { entre } \\
1468,9 \mathrm{~kg} / \mathrm{ha} \mathrm{e} \\
2680,4 \mathrm{~kg} / \mathrm{ha}\end{array}$ \\
\hline $\begin{array}{c}\text { Total } \\
\text { de dias }\end{array}$ & 23 & 21 & 23 & 24 & 20 & 23 & 20 & 23 & 19 & 22 & 22 & 19 \\
\hline $\begin{array}{c}\text { Menos } \\
\text { chuvos } \\
0\end{array}$ & 79,6 & 97,5 & 37,7 & 51,3 & 69,8 & 41,8 & 56,8 & 81,0 & 51,4 & 122,2 & 1099,4 & $1468,9 \mathrm{~kg} / \mathrm{ha}$ \\
\hline $\begin{array}{c}\text { Total } \\
\text { de dias }\end{array}$ & 2 & 4 & 2 & 2 & 3 & 3 & 5 & 3 & 7 & 3 & 3 & 5 \\
\hline
\end{tabular}

\section{Precipitação acima da habitual (normal).}

Dos 30 anos-safra analisados (1982/1983 a 2011/2012), foram registrados 5 anos-safra com precipitação acima da habitual. Notou-se a inexistência de baixos rendimentos, ou seja, menor que $1468,9 \mathrm{~kg} / \mathrm{ha}$. Os rendimentos médios, entre $1468,9 \mathrm{~g} / \mathrm{ha}$ até $2680,4 \mathrm{~kg} / \mathrm{ha}$, totalizaram $80 \%$ dos registros do total de registros. Por fim, os altos rendimentos, acima de 
$2680,4 \mathrm{~kg} / \mathrm{ha}$, totalizaram $20 \%$ dos registros de precipitação abaixo da habitual (quadro 5 e 6).

Quadro 5: Precipitação acima do habitual (normal) - 5 registros

\begin{tabular}{|c|c|c|}
\hline Rendimento & Ano-safra & $\begin{array}{c}\text { Total de } \\
\text { registros }\end{array}$ \\
\hline Alto & safra 2009/10 & $1(20 \%)$ \\
\hline Médio & safra 1982/83; safra 1986/87; safra 1993/94; safra 1997/98; & $4(80 \%)$ \\
\hline Baixo & - & $0(0 \%)$ \\
\hline
\end{tabular}

Org.: SILVA, R. R. (2013)

Quadro 6: Dados anos-safra selecionados com precipitação acima do habitual no município de lbirubá-RS anos-safra com precipitação acima do habitual.

\begin{tabular}{|c|c|c|c|c|c|c|c|c|c|c|c|c|}
\hline \multirow[b]{2}{*}{$\begin{array}{c}\text { Meses } \\
\text { Anos- } \\
\text { safra }\end{array}$} & \multirow[b]{2}{*}{ set. } & \multirow[b]{2}{*}{ out. } & \multirow[b]{2}{*}{ nov. } & \multirow[b]{2}{*}{ dez. } & \multirow[b]{2}{*}{ jan. } & \multirow[b]{2}{*}{ fev. } & \multirow[b]{2}{*}{ mar } & \multirow[b]{2}{*}{ abr. } & \multirow[b]{2}{*}{ maio } & \multirow[b]{2}{*}{$\begin{array}{c}\text { Precip } \\
\text { média }\end{array}$} & \multirow[b]{2}{*}{$\begin{array}{c}\text { Precip. } \\
\text { total }\end{array}$} & \multirow[b]{2}{*}{$\begin{array}{l}\text { Rendimento } \\
\text { médio (kg/ha) }\end{array}$} \\
\hline & & & & & & & & & & & & \\
\hline $\begin{array}{c}1982 / 8 \\
3\end{array}$ & 238,2 & 239,5 & 466,2 & 151,7 & 88,7 & 319,8 & 125,3 & 342,2 & 276,7 & 249,8 & 2248,3 & 2040 kg/ha \\
\hline $\begin{array}{c}1986 / 8 \\
7 \\
\end{array}$ & 106,6 & 169,2 & 384,3 & 142,0 & 164,3 & 145,0 & 74,1 & 455,6 & 227,9 & 207,6 & 1869,0 & $1800 \mathrm{~kg} / \mathrm{ha}$ \\
\hline $\begin{array}{c}1993 / 9 \\
4 \\
\end{array}$ & 95,8 & 93,5 & 351,1 & 408,1 & 76,8 & 295,8 & 102,7 & 270,1 & 159,6 & 205,9 & 1853,5 & $1.900 \mathrm{~kg} / \mathrm{ha}$ \\
\hline $\begin{array}{c}1997 / 9 \\
8\end{array}$ & 82,3 & 595,7 & 477,4 & 164,4 & 136,6 & 507,5 & 104,4 & 216,0 & 66,0 & 261,1 & 2350,3 & $2.400 \mathrm{~kg} / \mathrm{ha}$ \\
\hline $\begin{array}{c}2009 / 1 \\
0\end{array}$ & 438,1 & 146,9 & 449,6 & 119,6 & 334,5 & 194,3 & 48,7 & 188,3 & 127,2 & 227,5 & 2047,2 & $2.880 \mathrm{~kg} / \mathrm{ha}$ \\
\hline $\begin{array}{l}\text { Média } \\
\text { mensal }\end{array}$ & 186,4 & 217,7 & 169,9 & 141,6 & 167,5 & 157,7 & 121,5 & 172,3 & 141,8 & 164,0 & 1476,4 & $2080 \mathrm{~kg} / \mathrm{ha}$ \\
\hline $\begin{array}{l}\text { Mín. } \\
\text { precip. }\end{array}$ & 54,0 & 35,7 & 7,3 & 42,8 & 46,5 & 19,3 & 23,2 & 14,6 & 12,4 & 89,2 & 803,2 & $600 \mathrm{~kg} / \mathrm{ha}$ \\
\hline $\begin{array}{l}\text { Desvio } \\
\text { padrão }\end{array}$ & 106,7 & 120,2 & 132,3 & 90,3 & 97,7 & 116,0 & 64,7 & 91,3 & 90,4 & 41,9 & 377,0 & $611,5 \mathrm{~kg} / \mathrm{ha}$ \\
\hline $\begin{array}{l}\text { Máx. } \\
\text { precip. }\end{array}$ & 438,1 & 595,7 & 477,4 & 408,1 & 390,8 & 507,5 & 288,1 & 455,6 & 366,1 & 261,1 & 2350,3 & 3300 kg/ha \\
\hline \multicolumn{12}{|c|}{ Classificação dos anos-padrões de precipitação em mm } & $\begin{array}{l}\text { Classif. dos } \\
\text { rendim. kg/ha }\end{array}$ \\
\hline $\begin{array}{l}\text { Muito } \\
\text { chuvos } \\
\text { o }\end{array}$ & 293,1 & 337,8 & 302,2 & 231,9 & 265,1 & 273,7 & 186,2 & 263,6 & 232,2 & 205,9 & 1853,4 & $2680,4 \mathrm{~kg} / \mathrm{ha}$ \\
\hline $\begin{array}{c}\text { Total } \\
\text { de dias }\end{array}$ & 5 & 5 & 5 & 4 & 7 & 4 & 5 & 4 & 4 & 5 & 5 & 6 \\
\hline $\begin{array}{l}\text { Habitu } \\
\text { al }\end{array}$ & $\begin{array}{l}293,1 \\
-79,6\end{array}$ & $\begin{array}{l}337,8 \\
-97,5\end{array}$ & \begin{tabular}{|}
302,2 \\
$-37,7$
\end{tabular} \mid & \begin{tabular}{|}
231,9 \\
$-51,3$
\end{tabular} & $\begin{array}{c}265,1 \\
4- \\
69,8 \\
\end{array}$ & $\begin{array}{c}273,7 \\
3- \\
41,8 \\
\end{array}$ & \begin{tabular}{|}
186,2 \\
$-56,8$
\end{tabular} & $\begin{array}{l}263,6 \\
-81,0\end{array}$ & $\begin{array}{l}232,2 \\
-51,4\end{array}$ & $\begin{array}{c}205,9 \\
- \\
122,2 \\
\end{array}$ & $\begin{array}{c}1853,4 \\
- \\
1099,4\end{array}$ & $\begin{array}{c}\text { entre } \\
1468,9 \mathrm{~kg} / \mathrm{ha} \mathrm{e} \\
2680,4 \mathrm{~kg} / \mathrm{ha}\end{array}$ \\
\hline $\begin{array}{c}\text { Total } \\
\text { de dias }\end{array}$ & 23 & 21 & 23 & 24 & 20 & 23 & 20 & 23 & 19 & 22 & 22 & 19 \\
\hline $\begin{array}{c}\text { Menos } \\
\text { chuvos } \\
0\end{array}$ & 79,6 & 97,5 & 37,7 & 51,3 & 69,8 & 41,8 & 56,8 & 81,0 & 51,4 & 122,2 & 1099,4 & $1468,9 \mathrm{~kg} / \mathrm{ha}$ \\
\hline $\begin{array}{c}\text { Total } \\
\text { de dias }\end{array}$ & 2 & 4 & 2 & 2 & 3 & 3 & 5 & 3 & 7 & 3 & 3 & 5 \\
\hline
\end{tabular}

Org: SILVA, R. R. (2013) 
Segundo Farias; Nepomuceno; Neumaier (2007) a necessidade total de água na cultura da soja, para obtenção de máximo rendimento, varia entre 450 a $800 \mathrm{~mm} /$ ciclo fenológico. Ao considerar o ciclo vegetativo médio de 120 dias para a cultura da soja e o período recomendado para semeadura novembro, bem como, colheita em março de acordo com as recomendações da Embrapa Soja (2001), constatou-se que os totais de precipitação, dos meses referidos, do ano-safra $1982 / 83$ foi de $1151,7 \mathrm{~mm}$ de chuva; ano-safra 1986/87 foi de $909,7 \mathrm{~mm}$ de chuva; ano-safra 1993/94 foi de $1234,5 \mathrm{~mm}$ de chuva; ano-safra 1997/98 foi de $1390,3 \mathrm{~mm}$ de chuva; e ano-safra $2009 / 10$ foi de $1146,7 \mathrm{~mm}$ de chuva ficaram acima dos valores totais máximos exigidos (800mm/ciclo fenológico) para alto rendimento do grão.

\section{CONCLUSÕES}

Diante da analise dos dados e dos resultados, conclui-se que os anos de El Nino potencializam os altos rendimentos da soja, assim como os anos de La niña potencializam os baixos rendimentos do grão. Destaca-se ainda que o fator que mais influencia os rendimentos é a distribuição da precipitação durante o ciclo fenológico da soja.

A precipitação interfere nos rendimentos durante as fases de emergência (VE-Vn) que corresponde ao ultimo decênio de novembro e aos dois primeiros decênios de dezembro, segundo o calendário médio agrícola para a cultura da soja no Rio Grande do Sul, e a fase reprodutiva (R1-R6) a qual corresponde aos meses de janeiro e fevereiro. A precipitação abaixo e dentro dos padrões médios (normal) no mês de março mostrou-se benéfica porque auxilia na secagem do grão e na entrada das máquinas para a colheita.

Dessa forma, os totais de precipitação pluviométricas influenciam nos rendimentos da soja, mas verificou-se que a distribuição hídrica durante o ciclo fenológico, em destaque os momentos com maior exigência hídrica, fase vegetativa de emergência (VE-Vn) e reprodutiva de enchimento do grão, tornaram-se fundamentais para os rendimentos finais.

\section{REFERÊNCIAS BIBLIOGRÁFICAS}

AYOADE, J. O. Introdução à climatologia para os trópicos. São Paulo: Difel, 2007.

CONTI, J. B.; FURLAN. S.A. "Geoecologia. O clima, os solos e a biota".

ROSS, J. (Org). Geografia do Brasil. São Paulo: Edusp, 2005. p.47-59. 
MONTEIRO, C. A. F. Teoria e clima urbano: um projeto e seus caminhos. In: MONTEIRO, C. A. F.; MENDONÇA, F. (org.). Clima urbano. São Paulo: Contexto, 2003.

O estudo geográfico do clima. Cadernos Geográficos. Florianópolis, Ano I, n.1, maio, 1999.

Teoria e clima urbano. 25. São Paulo: IGEOG/USP, 1976.

A dinâmica climática e as chuvas no Estado de São Paulo: estudo geográfico em forma de atlas. São Paulo: USP/IGEOG, 1973.

Análise rítmica em climatologia: problemas da atualidade climática em São Paulo e achegas para um programa de trabalho. Climatologia. São Paulo, n.1, 1971.

O Clima da Região Sul.In: Geografia Regional do Brasil: Região Sul. Rio de Janeiro: IBGE, v.4, p. 117-169, 1963a.

MOTA, F. S. e AGENDES, M. O. de O. Clima agricultura no Brasil. Porto Alegre: SAGRA, 1986.

MOTA, F. S. Meteorologia agrícola. São Paulo: NOBEL, 1983.

OMETTO, J. C. Bioclimatologia Vegetal. São Paulo: CERES, 1981.

ORTOLANI, A. A.; PINTO H. S.; PEREIRA, A. R.; ALFONSI, R. R. Parâmetros climáticos e a cafeicultura. Instituto Brasileiro do Café, 1970. 27p.

PINTO, P. H. P.; abordagem preliminar sobre a distribuição espacial das chuvas no estado do Tocantins: anos Padrão do período de 1975-2005. REVISTA GEONORTE, Edição Especial 2, V.2, N.5, p.876-886, 2012.

PINTO, J. E. S. S.; NETTO, A. O. A. Clima Geografia e agrometeorologia: uma abordagem interdisciplinar. São Cristovão: Ed.UFS, 2008.

RIBEIRO, A. G. A. As escalas do clima. Boletim de Geografia Teórica. Rio Claro, n.23, 1993. pg. $288-294$

Climatologia Geográfica e a Organização do Espaço Agrário. In: Boletim de Geografia Teorética. Rio Claro: v.23, n. 45-46, p. 34-38, 1993. 
SANTOS, J. W. M. C. Ritmo Climático e Sustentabilidade Socioambiental da Agricultura Comercial da Soja no Sudeste de Mato Grosso. Revista do Departamento de Geografia, Pelotas, v. 17, [s./n.], p. 61-82. 2005.

SANTOS, M. J. Z. dos. Tendências das chuvas no nordeste paulista e problemas ligados com pesquisas em climatologia agrícola. In: Boletim de Geografia Teorética, v.23,p.39-45,1993.

Caracterização climática e variação das disponibilidades de água nos núcleos canavieiros paulistas. Rio Claro-SP. Revista de Geografia, n.4,p.1-21,1985.

\section{A importância da Variação do Regime Pluviométrico para a Produção} canavieira na região de Piracicaba (SP). 1979.69F. Dissertação (Mestrado em Geografia)Universidade de São Paulo, São Paulo, 1979.

SANTOS, E. R. dos; RIBEIRO, A G. Clima e agricultura no município de Caramandel - MG. In: SIMPÓSIO BRASILEIRO DE CLIMATOLOGIA GEOGRÁFICA, 5. 2002, Curitiba, Anais... Curitiba: UFPR, 2002.

SARTORI, M. G. B. A dinâmica do clima no Rio Grande do Sul: indução empírica e conhecimento científico. Terra Livre. São Paulo, ano 19, v.1, n.20, p.27-49. jan/jul.2003.

Clima e percepção. Tese (Doutorado em Geografia). Universidade de São Paulo, São Paulo, 2000.

.Distribuição das chuvas no Rio Grande do Sul e a variabilidade têmporo-espacial no período de 1912-1984. In: V SIMPÓSIO DE GEOGRAFIA FíSICA APLICADA, 1993, São Paulo. Anais... São Paulo: Departamento de Geografia/FFLCH/USP, 1993. p.275 -280.

.As variações pluviométricas e o regime das chuvas na Região Central do Rio Grande do Sul. Boletim de Geografia Teorética. Rio Claro, n.23, vol. 45-46, 1993. p.70-84.

A Circulação atmosférica regional e os principais tipos de tempo no inverno do Rio Grande do Sul, Brasil. Ciência e Natura. Santa Maria, n15, p.69-93, 1993.

.O clima de Santa Maria, RS: do regional ao urbano. 1979. 166fl. Dissertação (Mestrado em Geografia) - Universidade de São Paulo, São Paulo, 1979. 
Artigo recebido em 08/01/2014.

Artigo aceito em 09/03/2014. 